\title{
A CONSTRUÇÃO DO DIREITO À CIDADE ENTRE O INTERESSE PÚBLICO E O INTERESSE DOS AGENTES DO MERCADO IMOBILIÁRIO: UM ESTUDO DE CASO A PARTIR DO PLANO LOCAL DE GESTÃO DE BARÃO GERALDO, EM CAMPINAS
}

\author{
THE CONSTRUCTION OF THE RIGHT TO THE CITY BETWEEN PUBLIC INTEREST AND \\ THE INTEREST OF REAL ESTATE MARKET AGENTS: A CASE STUDY ON THE MANAGE \\ LOCAL PLAN OF BARAO GERALDO, CAMPINAS
}

\author{
Josué Mastrodi ${ }^{1}$ \\ Gabriela Martins Isaac ${ }^{2}$
}

\section{Resumo}

Neste artigo temos por objetivo discutir a problemática relação entre os interesses privados e o interesse público na produção do espaço urbano, identificando certa fragilidade da Administração Pública em relação à construção do direito à cidade, em que os agentes públicos, ao promoverem o planejamento urbano, acabam visando mais aos interesses do mercado imobiliário que ao interesse público. Embora, segundo a normativa constitucional, este devesse ser priorizado pelo Administrador, a lógica de mercado se apresenta mais determinante que qualquer dever de promoção de direitos fundamentais ou de planejar a cidade como um local de convívio. Este problema é discutido a partir de um estudo de caso ocorrido na cidade de Campinas, SP, em que se descreve a tentativa bem-sucedida de transformação, por lei municipal, de área rural em área urbana sem qualquer verificação prévia, pela Administração Pública, de sua viabilidade, e a luta das instituições públicas para evitarem a utilização do novo espaço urbano segundo o interesse privado.

Palavras-chave: Direito à Cidade, Direito Urbanístico, Planejamento Urbano, Interesse Público, Captura do Administrador pelo Mercado.

\begin{abstract}
In this paper we aim to discuss on the problematic relation between private and public interests in the production of urban space, identifying certain fragility of Public Administration in the building of the right to the city, in which the public agents, when promoting public planning, eventually comply with real estate interests in a proportion greater than the public interests at stake. However, although according to constitutional rules public interest should be prioritized by Administrator, market rules are presented as more determinant than any duty to either promote fundamental rights or plan the city as a local of common living. This problem is discussed from a case study occurred in the city of Campinas, SP, Brazil, in which there is a succeeded attempt to transform, by city law, a private rural area in urban area without any previous study by Public Administration, as well as the struggle of public institutions to avoid the use of the new urban area exclusively as stated by private interests.
\end{abstract}

Keywords: Right to the city, Urban Law, Urban Planning, Public Interest, Administration captured by market.

\footnotetext{
${ }^{1}$ Doutor em Direito pela Faculdade de Direito da Universidade de São Paulo. Professor da Pontifícia Universidade Católica de Campinas. E-mail: mastrodi@puc-campinas.edu.br

2 Graduanda em Direito pela Pontifícia Universidade Católica de Campinas. Bolsista da FAPIC (PUCCampinas), membro do grupo de pesquisa Direito e Realidade Social da PUC- Campinas. E-mail: gabi.mgii@hotmail.com
} 


\section{INTRODUÇÃO}

Este artigo possui dois objetivos. O primeiro é apresentar estudo de um caso prático envolvendo a Fazenda Santa Paula, localizada no município de Campinas, SP, cuja gleba foi em grande parte transformada em área urbana pelo Poder Público sem qualquer concretização de vontade popular ou democrática, e mesmo após a lei de transformação dessa área ter sido declarada inconstitucional, a área foi mantida, à revelia do dever de planejamento urbano e respeito ao direito à cidade por parte da Administração Pública.

A partir daí, buscamos atingir o segundo objetivo, qual seja, a partir da análise do problema prático, construir um conceito de direito à cidade na perspectiva da necessidade de planejamento urbano voltado ao interesse público, portanto tornar explícita a concepção de que o espaço público deve ser organizado para garantir a satisfação dos interesses da totalidade de seus cidadãos, motivo pelo qual o Estado deve dispor de ferramentas propulsoras da conformação do espaço, quais sejam, as formas de intervenção administrativa nos espaços privados da cidade, de forma a adequá-los à vocação do território. Enfim, espera-se explicitar o dever da Administração Pública de exigir o cumprimento da função social da propriedade, função que é estabelecida segundo as normas de direito urbanístico.

É preciso ressaltar que o direito à cidade é entendido como um Direito Humano que ainda não está consolidado de modo claro sequer nos tratados internacionais. O direito à cidade se refere a um conjunto de direitos sociais, estes compreendidos como direitos fundamentais, e que devem se coordenar no sentido de que todo cidadão tenha direito a viver e a conviver no espaço urbano. Ademais, o direito à cidade é um direito ainda difuso, mas que se contrapõe, necessariamente, ao dever do Estado de planejar, administrar e organizar a cidade como um espaço democrático ao qual todos tenham acesso e usufruto. Conforme David Harvey (2013),

Saber que tipo de cidade queremos é uma questão que não pode ser dissociada de saber que tipo de vínculos sociais, relacionamentos com a natureza, estilos de vida, tecnologias e valores estéticos nós desejamos. 0 direito à cidade é muito mais que a liberdade individual de ter acesso aos recursos urbanos: é um direito de mudar a nós mesmos, mudando a cidade. Além disso, é um direito coletivo, e não individual, já que essa transformação depende do exercício de um poder coletivo para remodelar os processos de urbanização. A liberdade de fazer e refazer as nossas cidades, e a nós mesmos, é, a meu ver, um dos nossos direitos humanos mais preciosos e, ao mesmo tempo, mais negligenciados (HARVEY, 2013, s/p).

No caso da Fazenda Santa Paula, trata-se de espaço exclusivamente privado, que precisa se submeter a processo administrativo de loteamento para ser aproveitado economicamente. Não há 
dúvida que o proprietário tem o direito de realizar o que quiser em seu espaço, por exemplo, a construção de um condomínio de luxo.

Porém, em virtude do princípio da função social da propriedade urbana, e em termos normativos do Estatuto da Cidade e do Plano Diretor, é a Administração Pública municipal quem deve definir se a área deve ser utilizada para a construção de um condomínio residencial de luxo, voltado à moradia de poucas famílias e à especulação imobiliária do entorno, ou se eventual aprovação de projeto deveria condicionar o loteamento de forma a promover o direito à cidade e o direito social à moradia, segundo a função social da cidade e a função social da propriedade previstas, respectivamente, no Estatuto da Cidade e na Constituição da República.

Buscou-se dividir o artigo em quatro partes. Em um primeiro momento, pontuou-se sobre o contexto da urbanização que, por força da estrutura social vigente desde os tempos das Revoluções Francesa e Industrial, é coordenada e organizada pelo Estado que, embora devesse se pautar por interesses públicos, acaba capturado pelos interesses de mercado e acaba por promover planejamento urbano e políticas públicas fundadas mais em interesse privado que em interesse público. Em seguida, tratou-se da construção dos conceitos de direito à cidade e de planejamento urbano que, para além de conceitos teóricos, referem-se a princípios de caráter normativo que devem obrigar o Estado na promoção do interesse público. No terceiro item, apresentou-se o histórico da Fazenda Santa Paula e a exposição do estudo sobre parte da gleba transformada em área urbana. Por fim, foram apresentadas algumas considerações à guisa de conclusão.

\section{URBANIZAÇÃO PRIVATIZADA, ESTADO CAPTURADO}

As zonas rurais estão sendo absorvidas pela área urbana. Antigas áreas verdes têm sido cada vez mais transformadas em novas fronteiras da cidade, ora na forma de subúrbios, ora de distritos industriais, ora de condomínios de luxo, num movimento incessante de urbanização. Assim, hoje não se está nunca diante da cidade, mas quase sempre dentro dela. Esse movimento de urbanização crescente tende a transformar em urbana a sociedade como um todo. A partir desta perspectiva, é possível destacar uma característica essencial de todas as cidades, de todos os tempos e lugares, a cidade é um locus de convivência.

Para uma cidade ser construída, é necessário planejamento, que pressupõe organização. A construção da cidade depende de normas e regulações internas. Essas normas até poderiam ser postas por consenso, por meio de conselhos ou por participação popular. De todo modo, hoje é 
comum haver uma autoridade, de natureza jurídica, com atribuições para promover o planejamento urbano e a estruturação de normas visando à implementação das ações necessárias para execução desse planejamento. No âmbito do Estado de Direito, a autoridade com essa prerrogativa é, em regra, o chefe de governo municipal. ${ }^{3}$

A Administração Pública é fundamentada sobre dois princípios: o da supremacia do interesse público sobre o interesse privado e o da indisponibilidade do interesse público. 0 Administrador deve dar prioridade a interesses de ordem social e estatal, que visam ao bem de uma comunidade, coletividade ou da sociedade como um todo, e este interesse público deve estar presente tanto na produção da lei pelo Legislativo quanto na sua execução pela Administração.

A atuação do Administrador não deve se desviar da supremacia do interesse público. Sendo assim, o agente público não deve dar mais importância a interesses privados, sob pena de desvio de finalidade dos atos administrativo, o que determina a nulidade dos atos praticados e caracteriza hipótese de improbidade administrativa.

Para Renato Alessi, há dois tipos de interesse público: o interesse público primário e o interesse público secundário. Este se refere a interesses imediatos do aparelho administrativo, independentemente dos interesses da coletividade. Já o interesse público primário, objeto deste artigo, é aquele que a Administração deve perseguir no desempenho genuíno da função administrativa, uma vez que abarca os interesses da coletividade como um todo (ALESSI, 1958, p.179-181). O interesse secundário deve ser levado em conta, mas antes como mero instrumento para busca do interesse primário. O chamado regime jurídico-administrativo, determinante da supremacia do interesse público sobre o privado e que permite, entre outras atividades da Administração, o planejamento urbano e a promoção do direito à cidade, se refere necessariamente a esse interesse público primário.

As normas urbanísticas e a própria construção do direito à cidade não têm refletido o interesse público primário, mas sim o interesse concreto de particulares, determinado por grupos detentores de grande poder econômico, luta que tem sido vencida pelos agentes econômicos do mercado imobiliário, ainda que haja profusão de normas de proteção do interesse público que, em tese, determinariam o resultado dessa luta em sentido diverso.

Nesse sentido, a cidade passa a ser vista essencialmente vivida não mais como um espaço social, político, complexo e cultural, pois transformada pura e simplesmente em um negócio ou

3 Ou, em regiões metropolitanas, pelo Conselho de Desenvolvimento (cf., a este respeito, a Lei Complementar Estadual no 870/2000, que criou a Região Metropolitana de Campinas). 
numa mercadoria. Não se podendo negar que há, de fato, a realização de planejamento urbano, porém esse planejamento é feito para a circulação de mercadorias e não para a convivência ou circulação das pessoas. O mercado imobiliário atribui o caráter de mercadoria aos imóveis e a toda a organização do espaço urbano visando prioritariamente a valorização imobiliária, afastando, com isso, o cumprimento da função social da cidade prevista no artigo 70 do Plano Diretor de Campinas. ${ }^{4}$

Nas grandes metrópoles, é fácil identificar territórios diferenciados, onde cada cidadão conhece seu local e se sente deslocado nos demais. Este fenômeno de apartação do espaço urbano segundo as classes sociais é conhecido como segregação espacial. ${ }^{5}$ Com isso, a criação de condomínios fechados, separação de local de trabalho em relação aos locais de moradia e separação de classes sociais em bairros distintos são exemplos de segregação.

A segregação é um fenômeno que faz com que, nas cidades, existam bairros pobres e bairros ricos. Os bairros tidos como pobres carecem de infraestrutura urbana, como mercados, postos de saúde, escolas, creches e praças. Muitas vezes, sequer há sistemas de fornecimento de água, captação de esgoto ou de energia elétrica. Além disso, para que a população desse bairro tenha acesso aos centros da cidade ou a quaisquer locais com serviços públicos, é necessário se deslocar por meio de transporte público que, via de regra, deixa a desejar.

A existência de territórios segregados não seria algo tão ruim se houvesse fácil acesso entre os bairros pobres, sem serviços, e os ricos, urbanizados. Se o transporte de um bairro pobre para o bairro rico fosse fácil seria um problema a menos. Contudo, isto não costuma acontecer na realidade. Se houvesse fácil acesso, praticamente não haveria segregação. Ademais, sempre que há um processo de urbanização nos bairros pobres, ou seja, quando o bairro que carece de serviços e equipamentos públicos passa a tê-los, ele se valoriza e expulsa os pobres que ali moram para outros lugares, geralmente mais afastados, e invariavelmente sem os serviços recém-instalados.

Com isso, o que mais espanta nesse processo de segregação, é o fato de ele não causar perplexidade ou constrangimento aos cidadãos nem ao Administrador que, à revelia do princípio constitucional da impessoalidade, promove tratamento desigual das áreas segregadas, em que grandes periferias não são atendidas por serviços de luz, água ou esgoto, ou equipamentos

\footnotetext{
${ }^{4}$ Disponível em: https://www.leismunicipais.com.br/plano-diretor-campinas-sp. Acesso em 07 de janeiro de 2016.

${ }^{5}$ ROLNIK, Raquel. KLINK, Jeroen. Crescimento econômico e desenvolvimento urbano: por que nossas cidades continuam tão precárias? Disponível em Novos estud. CEBRAP, n. 89, São Paulo, p. 89-109, Mar. 2011. Disponível em http://dx.doi.org/10.1590/\$0101-33002011000100006. Acesso em 10 de janeiro de 2016.
} 
públicos de saúde, educação e segurança, em clara expressão de uma política discriminatória que potencializa e aumenta o estado de segregação urbana.

Nesse sentido, é comum existirem áreas urbanas que não são sequer urbanizadas; ou seja, mesmo o Plano Diretor tendo demarcando determinada área como local urbano, esta carece dos elementos essenciais que o caracterizam como solo urbano, ou seja, há nesses locais a ausência sistemática e eloquente de infraestrutura urbana, formada por serviços e equipamentos públicos.

Por outro lado, há locais sem qualquer infraestrutura urbana, e localizados em zona rural que, por força de interesses privados, de algum modo obtêm autorização municipal para serem transformados em área urbana. E consegue-se, após tal aprovação, exercer pressão política no sentido de a Administração Pública prover, para aquela área, os equipamentos e serviços públicos que deveriam, antes, ser levados às demais áreas urbanas que já se encontram densamente povoadas. Este é exatamente o caso objeto de estudo nesta pesquisa, a Fazenda Santa Paula, localizada na zona rural do Distrito de Barão Geraldo, no município de Campinas, SP.

Boa parte da área dessa Fazenda Santa Paula foi transformada em área urbana pela Lei municipal n. 10.617/2000. Um local afastado da área urbana, sem qualquer relação com a cidade. Um local de propriedade de uma única dona, uma pessoa jurídica de direito privado cuja atividade econômica está ligada primordialmente ao mercado financeiro.

Embora tornado urbano, o local não possui nenhuma característica de cidade, não possui moradores, não possui produção além de agrícola, e não exerce nenhuma função social de cidade simplesmente porque não há cidade naquela área. Apesar de se ter feito referência, na exposição de motivos do projeto dessa Lei municipal, a uma inexistente vocação industrial daquela área, o interesse da proprietária estava na transformação da área em um condomínio residencial fechado, de alto padrão, a ser construído assim que a Prefeitura procedesse a ligação daquela área aos sistemas de fornecimento de água, esgoto e energia elétrica e o asfaltamento das ruas a serem abertas conforme previsão de loteamento da área etc.

A proprietária sofreu uma derrota judicial. Houve ação civil pública e, posteriormente, ação de inconstitucionalidade contra essa Lei municipal, que a declarou inconstitucional e que, portanto, deveria determinar o regresso da área à condição anterior. Contudo, o Tribunal de Justiça modulou os efeitos de sua decisão para permitir a construção em boa parte da área, mantendo o status de área urbana e permitindo a construção de um condomínio de luxo, muito embora essa construção não foi iniciada, entre outros movidos, segundo a Secretaria de Planejamento da Prefeitura de 
Campinas, porque não há nenhum pedido de loteamento ou de licença para construir relativos ao local.

Percebe-se como o Poder Público, no presente caso, representado pelo Poder Legislativo, foi capturado por interesses privados. Tudo foi formalizado de modo a parecer que o interesse público ou a vontade democrática determinou a criação de uma área urbana, quando na verdade ela foi constituída sem qualquer interesse popular ou público, sem qualquer necessidade política ou planejamento urbano.

O Poder Público, embora ainda no exercício de suas funções institucionais, acaba por delegar sua prerrogativa para agentes do mercado imobiliário. As normas continuam a ser formalmente baixadas pelo Poder Público, porém o conteúdo dessas normas parece feito para proteger interesses que não são democráticos ou públicos, E se a cidade é construída a partir de interesses privados, mais propriamente interesses de mercado, tudo o que se planejar para o espaço urbano tende a tratá-lo como uma mercadoria, a ser vendida a quem pagar mais por ela.

\section{DIREITO À CIDADE, DIREITO AO PLANEJAMENTO URBANO}

Com isso, pode-se notar uma conexão íntima entre o desenvolvimento do sistema econômico e a urbanização. Como pontua Henri Lefebvre, em sua obra Direito à Cidade, sobre urbanismo ou filosofia urbanística, que nada mais é do que a compreensão do espaço, do território, da maneira mais completa possível e não de forma desintegrada (LEFEBVRE, 2008, p. 48).

O grande problema é que, todas as vezes em que se realiza uma atividade ou uma intervenção social, é necessário que, antes, se decida começar de um lugar, de algum modo, visando a um grupo específico. E essa prerrogativa, decidir onde, como, quando e para quem agir, é uma discricionariedade atribuída exclusivamente ao Administrador Público que, em regra, decide começar pela estrutura que vai permitir a circulação de mercadorias, e não a circulação ou o bemestar das pessoas.

Porém, capturado pelos interesses de mercado, o Administrador assume tais interesses como se fossem interesse público e os aplica em seu planejamento urbano, estruturando a cidade de maneira que a lógica de mercado se desenvolva em toda sua exuberância, com a circulação de pessoas condicionada à circulação das mercadorias. Com isso, a cidade é organizada de tal maneira que alguns lugares se tornam privilegiados, mas sempre visando à produção, ao acúmulo de capital, e não ao desenvolvimento da cidadania. 
Isto nos remete a uma comparação entre as cidades atuais e a cidade-Estado da Atenas de 400 a.C., a polis, em que o conceito de cidadão não se referia à dimensão espacial da cidade e sim à sua dimensão política, ou seja, o conceito de cidadão não se referia ao morador da cidade, mas ao indivíduo que, por direito, podia participar da vida política. A cidadania estava associada a quem possuía a propriedade das terras agrícolas que correspondiam ao território da cidade-Estado. Com isso, na polis, quem decidia o "destino" da cidade -o que hoje poderíamos chamar de planejamento urbano e execução de políticas públicas- eram somente os proprietários e não todos os moradores.

No Estado de hoje, embora todos os cidadãos tenham o direito de se manifestar sobre os destinos de sua cidade, ainda que por meio de democracia representativa ou participativa, o fato é que os proprietários de grandes espaços dentro da terra urbana acabam por determinar ou condicionar, pela sua condição de proprietários, o planejamento urbano realizado pelo Administrador. Nesse sentido, ainda que todos sejam cidadãos e tenham o direito de exercer, hoje, sua cidadania, na prática o que se nota é que os grandes proprietários continuam a exercer o poder de definir os rumos da cidade.

Isto parece um tanto quanto contraditório quando pensamos em um conceito de cidade que é um local onde as pessoas vivem de forma coletiva, onde elas possuem (ou deveriam possuir) moradias adequadas e condições para realização de direitos básicos, como acesso a saúde, a educação e a transporte público para seu local de trabalho ou de lazer.

A vida em coletividade exige uma certa gestão do espaço público, gestão esta que deveria ser realizada por uma Administração voltada à satisfação do interesse coletivo dos moradores da cidade como um todo. No entanto, isto não ocorre na vida real, já que os interesses promovidos, caros ao mercado imobiliário, tendem a criar espaços de exclusão, produzindo uma cidade segregada, ou uma "não-cidade", já que os espaços públicos não são planejados para todos, mas apenas para alguns. A segregação espacial já está presente nos próprios Planos Diretores, que dividem a cidade em zonas e a organizam visando à produção do espaço segundo a eficiência econômica em vez de segundo a promoção de direitos. Esse direcionamento culmina por criar a figura do não-cidadão, que são todos aqueles que compõem a grande maioria dos que vivem na cidade, mas que não participam nem usufruem dela. ${ }^{6}$

\footnotetext{
${ }^{6} \mathrm{O}$ Grupo de Pesquisa de que são membros os autores deste artigo possui pesquisas em desenvolvimento especificamente sobre a questão da não-cidadania dos moradores da cidade, decorrentes de sua exclusão do processo de produção do espaço urbano e, consequentemente, sua exclusão do território e da possibilidade de uso da cidade ou de seu convívio nas áreas urbanas. Tais pesquisas serão oportunamente publicadas.
} 
Estes "excluídos", que na prática perfazem a maioria da população, ao mesmo tempo em que são excluídos, são justamente os que mais dependem da cidade para sua sobrevivência, e porque a cidade Ihes é negada, como se dela não pudessem fazer parte, vivem como podem, autoconstruindo, dividindo a moradia, ocupando ou invadindo locais, não tendo condições mínimas de uma moradia digna, mas morando onde conseguirem.

Em termos jurídicos, porém, não há nenhuma justificativa para a segregação socioespacial e para a falta de integração desses excluídos à cidade e às condições de exercício de sua cidadania. O Estado está integralmente submetido a normas, tanto de natureza constitucional e interna, quanto de natureza internacional, que impõem a integração de todos os cidadãos ao convívio na cidade, que impõe o planejamento urbano e ao exercício da função social da cidade. Os interesses privados, em geral representados pelos interesses do mercado imobiliário, contudo, não permitem a inclusão, pois atuam no sentido de ampliar a situação de segregação. O Planejamento deve ser feito por diretrizes a serem construídas coletivamente, por meio da participação popular em audiências públicas, em especial na criação dos Planos Diretores. Não obstante, quem participa dessas audiências públicas são prepostos do mercado imobiliário, justamente para legitimar, pelo instrumento de participação popular, a captura do Estado pelo interesse privado.

A organização do Estado de Direito com base na Declaração dos Direitos do Homem e do Cidadão se deu em 1789 após a Revolução Francesa, cujo slogan, "liberdade, igualdade e fraternidade", expressava a organização de uma estrutura social que em tese serviria para prestar serviços ao povo, mas que na verdade passou a servir quase que exclusivamente aos interesses do grupo econômico que ascendeu ao poder político, a burguesia revolucionária. Em outras palavras, o Estado de Direito, que surgiu com propósito de promover o direito público, promove interesses privados, em regra os interesses dos grandes empresários, desde sua origem.

Essa captura do Estado pelo mercado não se deu apenas no cenário político-institucional, mas também e principalmente no plano socioespacial. A cidade é um espaço que foi apropriada pelos empresários, e toda estrutura urbana tem sido planejada, desde os tempos da outra revolução, a industrial, visando ao escoamento da produção e não ao assentamento dos cidadãos. As cidades nunca foram planejadas para o bem-estar das pessoas, mas para a circulação das mercadorias. As pessoas acabam se beneficiando de boas ruas ou de boas estradas, que foram construídas mais para compra e venda da produção e realização de negócios mercantis que para poder visitar um parente ou um amigo. 
Isto significa que a ação do Poder Público no espaço urbano que emerge neste processo, antes de mais nada, tende a favorecer ao escoamento da produção, à obtenção de lucro. O espaço urbano sempre se apresentou e sempre foi construído como o campo de investimento do capital, ou seja, a forma de ocupação da terra urbana visa prioritariamente ao retorno financeiro, organizada em lotes facilmente mensuráveis para que a eles possa se atribuir um preço, maior ou menor conforme o grau de urbanização daquela localidade.

Os serviços e equipamentos públicos essenciais à qualidade de vida dos moradores são, antes, um fator de valorização do preço dos lotes urbanos. A lógica de mercado é e sempre foi um parâmetro fundamental no planejamento e na condução de quaisquer políticas de ocupação e uso do solo urbano, planejamento este que é feito pelo Estado e que, não obstante seu dever de priorizar interesses públicos, acaba por organizar a cidade segundo esses interesses privados.

A cidade tem sido construída por meio de lotes e loteamentos, conjunto composto por área de terra urbana ou urbanizável com determinada dimensão e ligada às redes de infraestrutura urbana em funcionamento. ${ }^{7}$ O loteamento pressupõe que naquela área exista uma infraestrutura urbana, ou seja, antes de lotear, haveria a necessidade de naquele local passar rede de água, esgoto, energia, sendo estas condições mínimas para se viver com dignidade em uma cidade, condições, porém, que já são negadas em vários bairros densamente povoados de inúmeras cidades, e não apenas de Campinas.

Por isto, o terreno a ser loteado deve estar servido da infraestrutura urbana que garanta a dignidade de vida para as pessoas que ali irão residir. O cidadão não ter acesso à rede de abastecimento de água, ou à de energia elétrica, não haver na região equipamentos públicos de saúde pública ou de educação é situação inaceitável, pois tais serviços são atualmente compreendidos como um dever do Estado ao atendimento aos direitos mais básicos do cidadão. Ou seja, urbanização pressupõe a criação de terra urbana, terra valorizada no mercado pela instalação de equipamentos e serviços públicos.

Desta maneira, se nota que o próprio espaço urbano é uma mercadoria cujo preço é estabelecido em função de atributos físicos e em decorrência do local em que ele se encontra (acessibilidade a centros de serviços ou negócios e/ou próximo a areais valorizadas da cidade). E também, a valorização de um local depende dos investimentos públicos e privados naquele espaço.

\footnotetext{
${ }^{7}$ A dissociação entre lote e infraestrutura pode se dar em apenas dois casos. O primeiro quando se tem o loteamento ilegal, sobretudo o clandestino, que constitui crime contra a Administração Pública (art. 50 da Lei no 6.766/79, que exige o dolo) e o segundo que é a situação do transcurso do tempo para a realização das obras exigidas, que é no máximo de 4 anos (art. 18, V, da Lei no 6.766/79).
} 
Sendo assim, estes elementos de investimento na infraestrutura são decisivos na lógica do mercado imobiliário, pois locais em que haja esses investimentos são mais valorizados.

Trata-se do fenômeno de ocupação das cidades brasileiras que o geógrafo Milton Santos nomeou de urbanização corporativa, isto é, "empreendida sob o comando das grandes firmas, constitui um receptáculo das consequências de uma expansão capitalista devorante dos recursos públicos, uma vez que esses são orientados para os investimentos econômicos, em detrimento dos gastos sociais" (SANTOS, 2013, p 105). 3. A Fazenda Santa Paula, de zona rural em zona urbana

No caso da Fazenda Santa Paula, a realidade não é diferente. Ao consultar o Plano Municipal de Habitação de Interesse Social de Campinas, aprovado pelo Conselho Municipal de Habitação em 8 de agosto de 2011, foi possível notar que o município de Campinas tem pela frente grandes desafios a serem superados como, por exemplo, o acesso à moradia digna, a reversão do processo de segregação sócio espacial, promoção da requalificação urbanística, a regularização fundiária dos assentamentos precários e a erradicação das moradias de áreas impróprias.

Neste mesmo Plano Municipal de Habitação é possível identificar os loteamentos aprovados em Campinas. Dentre os empreendimentos aprovados pelo Grupo de Análise e Aprovação de Projetos Habitacionais do Estado de São Paulo (GRAPROHAB) entre 2000 e novembro de 2010, consta o da Fazenda Santa Paula. No ano 2000, em Campinas, foi aprovada a Lei no $10.6171,{ }^{8}$ oriunda de um projeto de Lei apresentado pelo vereador Aparecido Donizeti Donaire, do Partido Popular Socialista (PPS), que alterou o Plano Local de Gestão do Distrito de Barão Geraldo (Macrozona 2), modificando o zoneamento de lotes voltados para a Rua Joseph Gorsin, no Jardim Melina I.

Algo extremamente curioso, e que passou despercebido por praticamente todos os atores desse processo, reside no fato que a tal Rua Joseph Gorsin, no Jardim Melina I, embora literalmente declarada no projeto de lei e também no texto da lei aprovada pela Câmara de Vereadores, não fica em Barão Geraldo, mas em outra localidade em outra ponta da cidade, próxima ao aeroporto internacional de Viracopos, conforme facilmente identificado por simples consulta a qualquer mapa do município ou mesmo por algum serviço de localização por satélite.

De todo modo, em que pese a existência desse erro, que não foi objeto de discussão em momento algum e sequer apontado, tal modificação tinha por escopo transformar, como de fato transformou, uma extensa área da zona rural em zona urbana do município de Campinas. A

\footnotetext{
${ }^{8}$ Disponível em: http://bibjuri.campinas.sp.gov.br/index/visualizaratualizada/id/87763. Acesso em 04 de janeiro de 2016.
} 
princípio, a finalidade essencial dessa lei visaria ao interesse público, conforme justificativa contida na exposição de motivos do então projeto de Lei: "Essa mudança se faz necessária, pois com o novo zoneamento, será permitido instalar nessa via pública, comércio e barracões, revitalizando o bairro e possibilitando o aumento de instalações que geram riquezas para o município."

O vereador não tratou de déficit habitacional, ${ }^{10}$ mas da promoção do desenvolvimento urbano pela instalação de estabelecimentos comerciais, que "gerariam riquezas para o município". Contudo, após a aprovação da Lei, o que se viu foi o pedido de instalação de um condomínio residencial de luxo naquela nova área urbana, sem qualquer relação com os motivos (comércio e indústria) apresentados pelo vereador para a aprovação da Lei no 10.617.

O Conselho Municipal de Desenvolvimento Urbano, reunido em 12 de maio de 1998, ano em que o projeto da Lei foi apresentado para votação na Câmara de Vereadores, analisou o projeto da Lei e posicionou-se contrário à sua aprovação, por entender tratar-se de proposta de mudança pontual de zoneamento e recomendou que o projeto fosse encaminhado à Secretaria Municipal de Planejamento como subsídio a um estudo mais amplo. Mesmo com estes pesares, a Lei foi aprovada dois anos depois, em 2000, sem qualquer modificação trazida pelo estudo proposto pelo Conselho.

As Leis de ordenação de espaço urbano deveriam decorrer de projetos propostos pela Administração Pública, pois esta detém a prerrogativa de realizar o planejamento urbano necessário à organização do território. Planejamento sem o qual torna-se inviável compreender e ordenar as necessidades para ocupação de um espaço e para prover o território com equipamentos públicos, como instalações de saneamento básico e energia elétrica, estruturação de escolas, creches, linhas de transporte público etc.

No presente caso, o projeto da Lei no 10.617 foi criado e levado à votação por iniciativa não da Administração Pública, mas de um membro da Casa Legislativa, que não realizou planejamento algum antes de apresentar seu Projeto de Lei. Além de não levar em conta inúmeras questões de ordem urbana e ambiental previstas pelo Plano Diretor ${ }^{11}$ da cidade de Campinas, não

\footnotetext{
${ }^{9}$ Justificativa na exposição de motivos da Lei no 10.617 dada pelo vereador Aparecido Donizeti Nonaire. em 16 de abril de 1998.

${ }^{10}$ Argumento utilizado pelo Ministério Público nas petições iniciais tanto da Ação Civil Pública quanto na Ação Direta de Inconstitucionalidade movidas contra a edição da Lei 10.617/2000

${ }^{11}$ Constituição da República, art. 182: A política de desenvolvimento urbano, executada pelo Poder Público municipal, conforme diretrizes gerais fixadas em lei, tem por objetivo ordenar o pleno desenvolvimento das funções sociais da cidade e garantir o bem-estar de seus habitantes.
} 
houve nenhum cuidado especial em identificar a área rural que seria transformada em urbana. Aliás, na ação civil pública movida pelo Ministério Público do Estado, a promotoria afirma que deveriam ter havido estudos de impacto ambiental por causa da proximidade do maior polo petroquímico da América Latina, que se localiza na vizinha Paulínia (REPLAN), que também ocasiona uma série de problemas socioambientais, como a contaminação do solo e também de pessoas por produtos químicos, a degradação da vegetação natural e a poluição dos corpos hídricos. ${ }^{12}$

No entanto, a área objeto da Lei № 10.617 fica a pelo menos oito quilômetros da divisa com o município de Paulínia e a uma distância muito maior em relação à REPLAN. Localiza-se dentro de uma fazenda privada, a dois quilômetros da divisa da zona rural com a zona urbana do distrito de Barão Geraldo, a uns dois ou três quilômetros de distância da rodovia SP 340, que liga Campinas não a Paulínia, mas a Jaguariúna. Trata-se de uma área com nítida vocação rural, ainda mais por se localizar no interior de uma fazenda, a Santa Paula. Em termos de promoção do interesse público, simplesmente não é possível imaginar a instalação nem de um condomínio de luxo, como têm sido o interesse da proprietária do imóvel, nem a instalação de barracões e galpões industriais, como motivou o vereador autor do Projeto de Lei.

A comunidade de Barão Geraldo tem procurado formas de garantir o desenvolvimento racional, planejado e ordenado dessa porção do município, preocupada na preservação da qualidade de vida para os que residem e para as gerações futuras. De certa forma, seus anseios foram atendidos em 1996, quando da aprovação da Lei no 9.199, ${ }^{13}$ que instituiu o Plano Local de Gestão Urbana de Barão Geraldo.

Esse plano foi elaborado por meio de um convênio da Prefeitura Municipal de Campinas com a Universidade Estadual de Campinas (Unicamp) e com a Pontifícia Universidade Católica de Campinas (PUCC), contando com uma equipe multidisciplinar de técnicos que estudaram profundamente as características e problemas do distrito, seus habitantes, sua vocação, sua

$\S 1$ 1 - O plano diretor, aprovado pela Câmara Municipal, obrigatório para cidades com mais de vinte mil habitantes, é o instrumento básico da política de desenvolvimento e de expansão urbana.

$\S 2$ o - A propriedade urbana cumpre sua função social quando atende às exigências fundamentais de ordenação da cidade expressas no plano diretor.

${ }^{12}$ Constituição do Estado de SP, art. 219: A saúde é direito de todos e dever do Estado.

Constituição do Estado de SP, art. 213: A proteção da quantidade e da qualidade das águas será obrigatoriamente levada em conta quando da elaboração de normas legais relativas a florestas, caça, pesca, fauna, conservação da natureza, defesa do solo e demais recursos naturais e ao meio ambiente.

${ }^{13}$ Disponível em: http://bibjuri.campinas.sp.gov.br/index/visualizaratualizada/id/91794. Acesso em 04 de janeiro de 2016. 
história, sua infraestrutura e ocupação, para que, junto com a comunidade, construíssem um modelo planejado de desenvolvimento racional para o distrito, garantindo para a sua população o equilíbrio necessário entre crescimento e qualidade de vida. Assim, as associações do distrito de Barão Geraldo alegaram ${ }^{14}$ que a nova Lei aprovada, no 10.617/00, estava em desacordo com a Lei que instituiu o Plano Local de Gestão Urbana de Barão Geraldo, Lei 9.199/96. Em termos claros, foi deixado de lado qualquer estudo de impacto ambiental ou o dever de realizar consulta pública ${ }^{15}$ sobre as necessidades da população daquela região sobre o aumento do perímetro urbano, condições estas expressamente exigidas pelo Plano Local de Gestão. ${ }^{16}$

O esforço de construir um Plano Local de Gestão Urbana de Barão Geraldo não resultou diretamente em melhorias para o distrito. Pelo contrário, nota-se que houve desvirtuamentos de conceitos do PLGU-BG e desrespeito ao macrozoneamento do Plano Diretor de Campinas. A Lei no 10.617/00 é um exemplo disso, pois ela transforma uma grande extensão de área rural em perímetro urbano, sem qualquer estudo técnico que habilitasse tal modificação.

Assim que a implantação, justamente naquela região transformada em área urbana pela Lei no 10.617, de um megacondomínio residencial da fazenda Santa Paula começou a ser noticiado, o Ministério Público do Estado de São Paulo, procurado por entidades de Barão Geraldo, promoveu uma Ação Civil Pública, em dezembro de 2003, com o objetivo de impedir a municipalidade de Campinas de realizar qualquer aprovação de projetos existentes na área delimitada pela Lei no 10.617/2000, pois esta afrontaria a legislação federal (Estatuto da Cidade) e municipal (Planos Diretor e de Gestão), contendo diversos vícios e irregularidades.

O promotor Rogério Rocha de Camargo sustentou sua ação apontando vícios que tornariam a lei irregular; por exemplos, vício de constitucionalidade por inobservância a normas insertas nas Constituições Federal e Estadual, inconsistências materiais entre a Lei no 10.617 e o Plano Diretor, o Plano de Gestão Urbana de Barão Geraldo e o Estatuto da Cidade, e vício de iniciativa (já que a proposta deveria ter sido apresentada pelo chefe do Poder Executivo e não por vereador). Esta ação tramitou perante a 4a Vara Cível da Comarca (ação no 4542/2003) e julgada

\footnotetext{
${ }^{14}$ Ação civil pública ambiental no 4542/2003.

15 Art.180 Constituição do estado de SP - No estabelecimento de diretrizes e normas relativas ao desenvolvimento urbano, o Estado e os Municípios assegurarão:

II - a participação das respectivas entidades comunitárias no estudo, encaminhamento e solução dos problemas, plano, programas e projetos que Ihes sejam concernentes;

${ }^{16}$ Art.2 são objetivos do PLGU/BG:

II - estimular de forma planejada e dentro do mais amplo consenso social o desenvolvimento das atividades de comércio e serviços, de forma a atender às necessidades locais e contribuir para a melhoria da qualidade de vida;
} 
em segunda instância pelo Tribunal de Justiça de São Paulo que, em acórdão datado de 2007 (apelação no 410.788.5/8-00), ${ }^{17}$ considerou por maioria de votos que tal ação não era a via adequada para discutir o que propunha, julgando-a extinta sem resolução de mérito.

Passados quatro anos após a decisão do Tribunal de Justiça, no ano de 2011, a Procuradoria Geral de Justiça do Estado de São Paulo apresentou ao Órgão Especial do Tribunal de Justiça de SP uma Ação Direta de Inconstitucionalidade de no 0052634- 90.2011.8.26.0000 ${ }^{18}$ contra a Lei no 10.617/2000, que teve por réus o Prefeito do Município de Campinas e o Presidente da Câmara Municipal de Campinas. Alegando que a Lei impugnada dispunha sobre o uso e ocupação do solo urbano e, portanto, possuía vício de iniciativa (deveria ter sido proposta pelo Executivo e não por parlamentar), pois a competência para interferir no planejamento, ocupação e uso do solo é exclusiva do Executivo e não do Legislativo. ${ }^{19}$

Além disso, este tipo de lei que interfere no uso do solo urbano depende de estudos prévios técnicos e audiência junto às entidades comunitárias que somente o Poder Executivo local, por meio de seus órgãos, estaria apto a realizar. ${ }^{20}$ É bem verdade que o projeto original da lei chegou a ser submetido a uma audiência pública em que houve um parecer desfavorável à sua aprovação, emitido pelo Conselho Municipal de Desenvolvimento Urbano. Assim, existe a clara

\footnotetext{
17 "Vistos, relatados e discutidos estes autos de APELAÇÃO CíVEL COM REVISÃO n 410.788-5/8-00, da Comarca de CAMPINAS, em que é recorrente o JUÍZO 'EX OFFICIO', sendo apelantes PREFEITURA MUNICIPAL DE CAMPINAS E OUTRA sendo apelado MINISTÉRIO PÚBLICO: ACORDAM, em Câmara Especial do Meio Ambiente do Tribunal de Justiça do Estado de São Paulo, proferir a seguinte decisão: 'POR MAIORIA, DERAM PROVIMENTO AOSRECURSOS, PARA EXTINGUIR A AÇÃO SEM JULGAMENTO DO MÉRITO E JULGARAM PREJUDICADOS OS REQUERIMENTOS POSTULADOS, VENCIDO EM PARTE O $2 O$ JUIZ, QUE DECLARARA VOTO. SUSTENTARAM ORALMENTE O DR. ANTÔNIO CARIA NETO E O ILMO. PROCURADOR DE JUSTIÇA, DR. TIAGO CINTRA ZARIF', de conformidade com o voto do Relator, que integra este acórdão."

18 "Vistos, relatados e discutidos estes autos de Direta de Inconstitucionalidade $n^{\circ}$ 005263490.2011.8.26.0000, da Comarca de São Paulo, em que é autor Procurador Geral de Justiça do Estado de São Paulo, são réus Prefeito do Município de Campinas e Presidente da Câmara Municipal de Campinas. ACORDAM, em Órgão Especial do Tribunal de Justiça de São Paulo, proferir a seguinte decisão: 'Julgaram a ação procedente, com modulação de efeitos. v.u. Fará declaração de voto o Exmo. Sr. Des. Grava Brazil, de conformidade com o voto do(a) Relator(a),que integra este acórdão'."

${ }^{19}$ Constituição do Estado de São Paulo, Art. 47. Compete privativamente ao Governador, além de outras atribuições previstas nesta Constituição:

II - exercer, com o auxílio dos Secretários de Estado, a direção superior da administração estadual;

${ }^{20}$ Constituição do Estado de São Paulo, Art. 154. Visando a promover o planejamento regional, a organização e execução das funções públicas de interesse comum, o Estado criará, mediante lei complementar, para cada unidade regional, um conselho de caráter normativo e deliberativo, bem como disporá sobre a organização, a articulação, a coordenação e, conforme o caso, a fusão de entidades ou órgãos públicos atuantes na região, assegurada, nestes e naquele, a participação paritária do conjunto dos Municípios, com relação ao Estado. $\S 2$ 2o - É assegurada, nos termos da lei complementar, a participação da população no processo de planejamento e tomada de decisões, bem como na fiscalização da realização de serviços ou funções públicas em nível regional.
} 
exigência da participação efetiva da população do Município na elaboração das diretrizes e normas concernentes ao desenvolvimento urbano.

Não se trata de simples regra e, sim, de verdadeira diretriz interpretativa de toda lei relativa ao desenvolvimento urbano. Com base nestes argumentos, a lei foi declarada inconstitucional pelo Tribunal de Justiça, porém não desde sua publicação e sim desde a data da concessão de liminar, com o objetivo de preservar as situações jurídicas consolidadas até o período daquela vigência da Lei.

Com isso, dos 3,5 milhões de $\mathrm{m}^{2}$ de área rural transformada em urbana pela Lei no 10.617, a Prefeitura já havia aprovado um loteamento com 400 lotes de 1 mil m², além das áreas reservadas à instalação de bens de uso comum do povo (ruas e praças) e das áreas de preservação ambiental (20\% da área total); ou seja, já houve aprovação, pela Prefeitura, do uso de cerca de um milhão de metros quadrados da nova área urbana exclusivamente para a instalação de um condomínio residencial de luxo.

Em contrapartida à liberação do empreendimento do condomínio de alto padrão, a Prefeitura teria definido à proprietária da área, a Vera Cruz Empreendimentos Imobiliários, do Grupo Alfa (o mesmo grupo empresarial titular do Banco Real antes de sua venda ao Banco ABNAnRo) que procedesse a construção de um hospital naquela mesma nova área urbana, uma filial do conhecido Hospital Sírio Libanês (conforme proposta apresentada pela própria Vera Cruz quando do pedido de aprovação da construção do condomínio). A Vera Cruz, por essa contrapartida, seria responsável pela instalação do hospital, desde a doação de área de $30 \mathrm{mil} \mathrm{m}^{2}$ para sua instalação até todos os gastos necessários para sua edificação, equipagem e operação, com custos estimados em 200 milhões de reais.

Assim, quando foi instaurada a Ação Direta de Inconstitucionalidade, foi deferida a intervenção da Sociedade Beneficente de Senhoras - Hospital Sírio Libanês, que pleiteou a improcedência da ação bem como a modulação dos efeitos de eventual procedência. Foi por esse motivo que o relator da ADI proferiu o seguinte voto:

....ante os fatos trazidos pelos interessados intervenientes, sobretudo pela Sociedade Beneficente de - Hospital Sírio Libanês -, na qualidade de amicus curiae, entendo manifesto o excepcional interesse social a justificar, com apoio no art. 27, da Lei $n^{\circ} 9.868 / 99,{ }^{21}$ a modulação dos efeitos da declaração de inconstitucionalidade, de modo que a presente decisão tenha eficácia, não desde a publicação da lei e, sim, desde a data da concessão da liminar nestes autos, para preservar as situações jurídicas consolidadas até então,

${ }^{21}$ Disponível em: http://www.planalto.gov.br/ccivil_03/leis//9868.htm. Acesso em 04 de janeiro de 2016. 
como a aprovação de empreendimentos sob a égide da legislação impugnada. ${ }^{22}$

Contudo, em reunião com a Coordenadora do Departamento de Aprovação de Projetos da Prefeitura de Campinas, na data de 11 de junho de 2014, foi esclarecido que, na verdade, não houve aprovação, pela Prefeitura, da instalação de nenhum hospital na região. O que dá a entender que a contrapartida não foi aceita ou mesmo sequer foi proposta pela Prefeitura, embora isto tenha sido utilizado como argumento pela Vera Cruz para conseguir, em que pese a inconstitucionalidade da Lei no 10.617, a manutenção dos projetos que já haviam sido apresentados à Prefeitura antes da instauração da Ação Direita de Inconstitucionalidade perante o Tribunal de Justiça.

Além disso, em agosto de 2014, os autores foram ao local objeto da referida lei e constataram que aquela área, tornada urbana por força da lei, encontra-se no interior da fazenda Santa Paula, a cerca de $2 \mathrm{~km}$ de distância do logradouro público mais próximo, que é a avenida Francisco Cândido Xavier, do bairro Village (distrito de Barão Geraldo). Ressaltou-se, ainda, que essa área urbana a que se refere a lei aparentemente não possui sistemas urbanos de saneamento básico ou fiação para fornecimento de energia elétrica.

Embora tornada urbana, aparenta manter destinação rural em todos os aspectos. Em que pese o Tribunal de Justiça ter autorizado a manutenção de situações jurídicas consolidadas durante a vigência da Lei 10.617, foi constatado que não há nenhuma construção no local, nem mesmo do tal hospital cuja construção estaria em franco andamento, segundo a Sociedade Beneficente de Senhoras, mas que, segundo consulta junto ao órgão responsável por aprovações de projetos da Prefeitura de Campinas, nenhum pedido foi feito no sentido de se aprovar a construção de condomínio ou do hospital.

Em função do reconhecimento da heterogeneidade das áreas do município de Campinas, foram definidas nove Macrozonas, considerando-se para esta definição os aspectos físicoterritoriais, socioeconômico e ambientais identificados a partir de leituras e diagnósticos produzidos no Plano Diretor. As informações a seguir foram retiradas do portal de internet da Prefeitura de Campinas. ${ }^{23}$

\footnotetext{
${ }^{22}$ ADI no 0052634-90.2011.8.26.0000. Disponível em: https://sglm.campinas.sp.gov.br//files/full/1aead43f177bf272f04887dfb9ba99839d854d65.pdf, p. 10. 23 Disponível em: http://www.campinas.sp.gov.br/governo/seplama/planos-locais-degestao/doc/mz2/PARTE_II_DIRETRIZES_E_PROPOSTAS2.pdf http://www.campinas.sp.gov.br/governo/seplama/planos-locais-degestao/doc/mz2/PARTE_I_CARACTERIZACAO.pdf. Acesso em 30de janeiro de 2016.
} 
A área referida pela Lei n. 10.617/2000 está circunscrita à macrorregião norte/nordeste do município (Macrozona 2), local predominantemente inserido no perímetro rural, apresentando somente algumas porções urbanas (Loteamento Bosque das Palmeiras, Vale das Garças e Village Campinas). É definida como Área de Controle Ambiental- ACAM, onde se deve controlar a urbanização e incentivar as características rurais.

Esta Macrozona 2 é subdividida em duas áreas de Planejamento em que uma corresponde à região do Vale das Garças, situada ao norte da Macrozona e a outra, na qual corresponde a lei em estudo desta pesquisa, que é a área predominantemente rural.

Portanto, a Macrozona 2 é tida como área com restrição à urbanização (ARU), sendo assim deverão ser mantidas as características rurais, com estabelecimento de critérios adequados de manejo das atividades agropecuárias, de exploração mineral e de parcelamento do solo. Contudo, A estrutura urbana atual da Macrozona 2 caracteriza-se pela descontinuidade em termos de ocupação e se apresenta com aglomerações urbanas inseridas na área rural

Constata-se, também, que nessa macrozona predominam na porção urbana loteamentos residenciais com ocupação horizontal, alguns usos comerciais e industriais e poucos pontos comerciais de caráter local, além da inexistência de equipamentos públicos adequados.

Na Macrozona 2, a maioria dos loteamentos residenciais foi concebida pelo padrão de chácaras de recreio e posteriormente regularizados pela Prefeitura, com utilização cada vez mais voltada para moradia, constituindo-se quase sempre em condomínios, pelas respectivas associações de moradores, porém com condições de infraestrutura ainda não solucionada Registram-se na zona urbana algumas áreas não urbanizadas muito distantes da área urbana consolidada, sem infraestrutura e sem nenhuma atividade, quer urbana, quer rural.

Segundo informações da Secretaria Municipal de Urbanismo, existem aprovados, mas ainda não implantados, 3 (três) loteamentos na Macrozona 2. São eles: Conjunto Residencial Aruanã, Mont Blanc Residence (parcialmente dentro da Macrozona 2) com área de 475.561,68 $\mathrm{m}^{2}$ e 262 lotes e Parque do Alecrins (também parcialmente dentro da Macrozona 2), com 473.694,00 $\mathrm{m}^{2}$ e 406 lotes. E existem em análise dois loteamentos: Residencial Grephen com área de 70.105,45 m² e 70 lotes e o loteamento Santa Paula, com área de 969.018,00 m².

Ademais, foi feito um requerimento à Prefeitura de Campinas para saber se houve aprovação da referida área estudada nesta pesquisa e se há cobrança de IPTU. O requerimento foi encaminhado à Secretaria de Planejamento - SEPLAN, que informou que não há tributação do IPTU para a área contida na Lei, justificando que se trata de área ainda não cadastrada na Prefeitura. 
Contudo, no próprio site da Prefeitura, como já mencionado anteriormente, e em conversa por email dos autores com funcionários da Prefeitura foi dito que o Decreto № 17.213, de 7 de dezembro de 2010, informado pela própria SEPLAN, foi revalidado pelo Decreto no 18.699, de 9 de abriu de 2015, portanto foi aprovada pela Prefeitura a transformação do local em área urbana. Porém, a proprietária (Vera Cruz Empreendimentos Imobiliários LTDA) jamais pagou IPTU sobre o imóvel.

Com isso, pode-se perceber que atualmente o perímetro urbano do município contido na Macrozona 2 apresenta-se fragmentado e desconexo, em decorrência de um crescimento urbano desordenado, dificultando seu planejamento e acarretando uma relação de dependência do Poder Público Municipal, notadamente na oferta de infraestrutura de transporte, energia elétrica e saneamento, dentre outros.

Por situarem-se como satélites urbanos da cidade de Campinas, os fragmentos de perímetro urbano da Macrozona 2 não apresentam por si só, uma massa crítica necessária ao seu próprio desenvolvimento ecossustentável. Não obstante, sua necessidade permanente de apropriação dos benefícios líquidos dos investimentos públicos e sua relação de dependência com o centro urbano, a Macrozona 2 recebeu novos fragmentos de perímetros urbanos por força da constitucionalidade da Lei № 10.617 de 15 de setembro de 2000, agravando sobremaneira seu quadro atual.

\section{CONSIDERAÇÕES FINAIS}

Com diferenças de grau e intensidade, todas as cidades brasileiras exibem problemas semelhantes e recorrentes. Problemas como o da falta de moradia adequada, da precariedade de transportes públicos, da escassez ou má distribuição de água, da falta de saneamento básico, entre outros.

Esse fenômeno de escassez dos recursos públicos se deve à já comentada urbanização corporativa, em que a cidade é organizada como um negócio controlado por grandes empresas que por consequência direciona os recursos públicos para obras e serviços de seu interesse, já que o uso de recursos para satisfação prioritária do interesse público traz ineficiência para o negócio.

A organização da cidade a partir de projetos que protejam o cidadão, o planejamento urbano visando à construção do direito à cidade, a promoção do espaço urbano segundo a função social da propriedade e da função social da cidade, ou seja, as ações estatais visando à realização de um direito humano que ainda se apresenta difuso, exatamente no sentido o sistema normativo 
impõe ao Estado e ao Administrador Público, não acontecem, bloqueadas por interesse privados de grupos que de há muito controlam e planejam o espaço urbano como simples extensão de suas propriedades particulares.

O estudo de caso da Fazenda Santa Paula serviu para comprovar, nessa realidade havida no município de Campinas, a ocorrência da captura do Estado e do Administrador por interesses privados e o planejamento urbano segundo estes interesses.

\section{REFERÊNCIAS}

\section{Bibliográficas}

ALESSI, Renato. Sistema Istituzionale del Diritto Amministrativo Italiano, 2 ed. Milão: Giuffrè, 1958.

HARVEY, David. O direito à cidade. Revista Piauí n. 82, julho de 2013, s/p. Versão digital disponível em: http://revistapiaui.estadao.com.br/edicao-82/tribuna-livre-da-luta-de-classes/o-direito-acidade. Acesso em 12 de março de 2015.

LEFEBVRE, Henri. O direito à cidade. Trad. Rubens Eduardo Frias. 4a ed. São Paulo, Centauro, 2006.

ROLNIK, Raquel. KLINK, Jeroen. Crescimento econômico e desenvolvimento urbano: por que nossas cidades continuam tão precárias? Novos estud. CEBRAP, n.89, São Paulo, p. 89-109, Mar.2011. Disponível em http://dx.doi.org/10.1590/S0101-33002011000100006. Acesso em 10 de julho de 2015.

SANTOS, Milton. A Urbanização Brasileira. São Paulo: Hucitec, 2013.

Legislativas

BRASIL. ASSEMBLEIA NACIONAL CONSTITUINTE. Constituição da República Federativa do Brasil, 1988.

CONGRESSO NACIONAL. Lei no 10.257/2001 (Estatuto da Cidade).

CAMPINAS. CÂMARA DE VEREADORES. Lei Complementar no 15/2006 (Plano Diretor).

Lei no 10.6617 (aprova o Plano de Gestão do Município. Macrozona 2 - Barão Geraldo).

CAMPINAS. CÂMARA DE VEREADORES. Lei no 10.671/2000.

Documentos oficiais do Poder Judiciário

SÃO PAULO. TRIBUNAL DE JUSTIÇA. Ação Civil Pública no 4542/2003 e Acórdão no 410.788.5/8-00.

TRIBUNAL DE JUSTIÇA. Ação Direta de Inconstitucionalidade no 0052634-90.2011.8.26.0000.

Trabalho enviado em 25 de fevereiro de 2016.

Aceito em 08 de abril de 2016.

Revista de Direito da Cidade, vol. 08, no 2. ISSN 2317-7721 pp.729-748 